\title{
Knowledge and Experience about Medical Emergencies among Dental Interns in Bangalore City
}

INTRODUCTION: Medical emergencies are very frequent in dental setting. It is imperative to judiciously manage these situation in clinical setting. Having correct knowledge about the medical emergencies and the management methods are crucial successful clinical practice.

AIM: To assess the knowledge and experience about medical Emergencies among Dental interns in Bangalore City. MATERIALS AND METHODS: A cross sectional study was conducted among 350 dental interns from sixteen dental colleges in Bangalore City using a structured questionnaire consisting of 14 item questions.

RESULTS: Syncope being the most commonly encountered medical emergency $(79.14 \%)$, followed by hypoglycaemia(17.14\%). About $49.71 \%$ respondents considered medical emergency training was moderate. $98 \%$ of them think that medical emergencies training is important. Knowledge of the presence of drugs and equipments in the emergency drug kit and the confidence with regard to using them was not satisfactory.

CONCLUSION: Dental graduates had a superficial knowledge of management of medical emergencies and use of drugs and equipments.

KEYWORDS: Dental Interns, Medical Emergencies, Knowledge

\section{INTRODUCTION}

A medical emergency can be described as any situation in which the patient's life may be at risk due to a failure of an effective oxygenated circulation to the vital organs. The dentist has the responsibility to identify the medical emergencies and initiate the management procedures at the earliest. ${ }^{1}$ An elaborate history of the patient enable the dentist to anticipate the potential adverse events that may precipitate during the treatment. ${ }^{2}$

Some drugs like anaesthetics, some procedures and the mere thought of dental treatment can cause stress and anxiety in the patients, these in turn can lead to a life threatening situation. ${ }^{3}$ Effective and successful management of life-threatening situations includes adequate education of the dentist, presence of emergency drug kit, education of the chair side assistant and provision for referral to the nearby healthcare facility. ${ }^{4}$

A dental graduate is expected to identify the medical problems in a patient during history recording, and they should be confident enough to provide basic life support, including positioning, airway maintenance, and circulation. They should be familiar with resuscitation drugs and emergency equipment (both modified for dental practice).
It's the prime duty of dentist to manage an emergency situation in the dental office with utmost care and responsibility. Insufficient training and lack of sufficient knowledge can lead to tragic consequences and sometimes even fatal. ${ }^{5}$

Keeping in mind the risk associated with dental treatment, it becomes important for the dental interns to have a thorough knowledge about medical emergencies and to take appropriate steps for the prevention and management of such emergencies in the dental clinic. The aim of this study is to assess the knowledge and experiences about medical emergencies among dental interns of various dental colleges in Bangalore City.

\section{MATERIALS AND METHODS}

The present study is a descriptive, cross-sectional questionnaire survey. Permission to conduct the study was obtained from the Principals of the respective dental colleges where the study was conducted. The study proposal was submitted for approval and clearance was obtained from the ethical review board of Oxford Dental College, Hospital and Research Center - Bangalore.

All the dental interns from 16 dental colleges in 
Bangalore City affiliated to the Rajiv Gandhi University of Health Sciences who were present during the study were selected for the study. Data were collected from 350 Interns of sixteen dental colleges in Bangalore City using a structured questionnaire consisting of 14 item questionnaire.

Verbal informed consent was obtained from the interns by disclosing that the data collected was for research purpose. Dental interns who agreed to participate in the survey were assured of confidentiality. A specially prepared and pretested format, exclusively designed for recording all the relevant data pertaining to general information was used. A pilot study was carried out on $10 \%$ of the population in order to check the feasibility and relevance of the prepared format. Questionnaire was tested for its validity and reliability before the main study.

Statistical analysis: The data analysis was done using the statistical software SPSS 20. Univariate and Bivariate frequency tables were generated. For selected variables associations were studied between gender and parameters using Chi square test. $\mathrm{p}$ value less than or equal to 0.05 was considered to be statistically significant.

\section{RESULTS}

Out of the 350 dental interns, $158(45.2 \%)$ were males and $192(54.8 \%)$ were females. About $44.8 \%$ males and $55.1 \%$ females consider that understanding of medical emergencies are very important.

Around $70 \%$ of dental interns have encountered one or the other medical emergencies in their undergraduate level. Syncope/faint was the most commonly encountered medical emergency with $79.1 \%$ respondents, followed by hypoglycemia $17.1 \%$ and allergic reactions $0.03 \%$.

According to $98 \%$ of dental interns, there is a need for medical emergency training at under graduate level and $68.3 \%$ of them had undergone medical emergency and basic life support training at undergraduate level. Only $26.7 \%$ felt that the training programme was good.

Among the knowledge regarding the emergency drugs adrenalin $(69.4 \%)$, glucose $(62.3 \%)$ and hydrocortisone (69.1\%) was considered as emergency drugs (Table 1). Females had better knowledge among the identification of these drugs $(\mathrm{p}=0.04)$, whereas males were more confident in using these drugs, adrenalin (72\%), glucose (63.3\%), hydrocortisone (71.5\%) (Table 2). Regarding the equipments oxygen face mask (91.1\%) and single use syringe (94.6\%) was identified whereas only limited knowledge was there regarding other equipments (Table 3). Majority of the study subjects (91.4\%) were confident in only using single use syringe (Table 4). About $57.4 \%$ were competent in using intramuscular injections whereas

\begin{tabular}{|c|c|c|c|c|c|c|c|c|c|}
\hline KIT & MALE & $\%$ & FEMALE & $\%$ & TOTAL & $\%$ & Z-value & P-value \\
\hline Adrenalin & 115 & 72.8 & 128 & 66.7 & 243 & 69.4 & -1.2350 & 0.2170 \\
\hline Aspirin & 59 & 37.3 & 89 & 46.3 & 148 & 42.3 & -1.6960 & 0.0900 \\
\hline Glucagon & 45 & 28.5 & 56 & 29.2 & 101 & 28.9 & -0.1410 & 0.8880 \\
\hline Glyceryl trinitrate & 64 & 40.5 & 93 & 48.4 & 157 & 44.8 & -1.4830 & 0.1380 \\
\hline Prednisolone & 30 & 18.9 & 50 & 26.0 & 80 & 22.8 & -2.0670 & $0.0390^{*}$ \\
\hline Chlorpheniramine & 36 & 22.8 & 69 & 35.9 & 105 & 30.0 & -0.3520 & 0.7250 \\
\hline Salbutamol & 52 & 32.9 & 84 & 43.7 & 136 & 38.8 & -0.8720 & 0.3830 \\
\hline Glucose & 100 & 63.3 & 118 & 61.5 & 218 & 62.3 & -0.8720 & 0.3830 \\
\hline Hydrocortisone & 113 & 71.5 & 129 & 67.2 & 242 & 69.1 & -1.9890 & $0.0470^{*}$ \\
\hline Midazolam & 113 & 71.5 & 129 & 67.2 & 242 & 69.1 & -1.0610 & 0.2890 \\
\hline Dextrose & 30 & 18.9 & 54 & 28.1 & 84 & 24.0 & -1.4600 & 0.1440 \\
\hline Oxygen & 70 & 44.3 & 96 & 50.0 & 166 & 47.4 & -2.3300 & $0.0200^{*}$ \\
\hline Atropine & 65 & 41.1 & 94 & 48.9 & 159 & 45.4 & -0.1750 & 0.8610 \\
\hline
\end{tabular}

Table 1. Distribution of study subjects according to gender and their agreement to the following drugs being part of emergency drug kit. ( ${ }^{*} \mathrm{p}<0.05$ was considered statistically significant) 


\begin{tabular}{|c|c|c|c|c|c|c|c|c|c|c|}
\hline DRUG & MALE & $\%$ & FEMALE & $\%$ & TOTAL & $\%$ & \multicolumn{2}{c|}{ Z-value } & P-value \\
\hline Adrenalin & 115 & 72 & 128 & 66.7 & 243 & 69.4 & 1.529 & 0.219 \\
\hline Aspirin & 59 & 37.3 & 89 & 46.3 & 148 & 42.3 & 2.885 & $0.0455^{*}$ \\
\hline Glucagon & 45 & 28.5 & 56 & 29.2 & 101 & 28.9 & 0.0198 & 0.4450 \\
\hline Glyceryl trinitrate & 64 & 40.5 & 93 & 48.4 & 157 & 44.9 & 2.204 & 0.0698 \\
\hline Prednisolone & 30 & 18.9 & 50 & 26.0 & 80 & 22.9 & 1.128 & 0.1455 \\
\hline Chlorpheniramine & 36 & 22.9 & 69 & 35.9 & 105 & 30.0 & 7.14 & $0.0037^{*}$ \\
\hline Salbutamol & 52 & 32.1 & 84 & 43.7 & 136 & 38.9 & 4.286 & $0.0195^{*}$ \\
\hline Glucose & 100 & 63.3 & 118 & 61.5 & 218 & 62.3 & 0.1239 & 0.3635 \\
\hline Hydrocortisone & 113 & 71.5 & 129 & 67.2 & 242 & 69.1 & 0.7622 & 0.193 \\
\hline Midazolam & 113 & 71.5 & 129 & 67.2 & 242 & 69.1 & 0.7622 & 0.193 \\
\hline Dextrose & 30 & 18.9 & 54 & 28.1 & 84 & 24.0 & 3.968 & $0.0235^{*}$ \\
\hline Oxygen & 70 & 44.3 & 96 & 50 & 166 & 47.4 & 1.128 & 0.1455 \\
\hline Atropine & 65 & 41.1 & 94 & 48.9 & 159 & 45.4 & 2.138 & 0.072 \\
\hline
\end{tabular}

Table 2. Distribution of study subjects according to their confidence in using emergency drug kit (considered with confident option only). ( ${ }^{*} \mathrm{p}<0.05$ was considered statistically significant)

the competency in using other methods were low (Table 5).

\section{DISCUSSION}

Medical emergencies are less frequent in clinical setting but once precipitates it's the duty of the dentist to identify and judiciously manage the emergency and prevent morbidity and mortality1. It is essentially important to have emergency kit at every dental setting because one out of three patients visiting dental clinics have a some medical problems. In the present study $94.8 \%$ of dental interns consider that understanding of medical emergency is very important. About $70 \%$ of dental interns out of which more number of females (55.9\%) have encountered one or the other medical emergencies in their undergraduate level. In a study conducted by Jodalli $\mathrm{S}$ et al. in 2012, 58.1\% of dental interns had experienced an emergency situation during their graduation. $^{2}$

According to Ehigiator $\mathrm{O}$ et al. previous studies done in the United States and Canada, have shown that syncope is the most common medical emergency seen by dentists. ${ }^{6}$ Our study also showed that Syncope/faint as the most commonly encountered medical emergency with $79.1 \%$, followed by hypoglycemia $17.1 \%$ and allergic reactions $0.03 \%$. About $55.4 \%$ females and $44.6 \%$ males feel that, there is a need for medical emergency training at under graduate level, this was supported by a studies done by Atherton GJ et al. in 2000, Adewole RA et al. in

\begin{tabular}{|c|c|c|c|c|c|c|c|c|}
\hline EQUIPMENTS & $\begin{array}{l}\text { MALE } \\
\text { YES }\end{array}$ & $\%$ & $\begin{array}{l}\text { FEMALE } \\
\text { YES }\end{array}$ & $\%$ & TOTAL & $\%$ & Z-value & P-value \\
\hline Oxygen face mask & 144 & 91.1 & 175 & 91.2 & 319 & 91.1 & 0.0349 & 0.9944 \\
\hline Single use syringe & 147 & 93.0 & 184 & 95.8 & 331 & 94.6 & 1.315 & 0.132 \\
\hline Pocket masks & 93 & 58.9 & 114 & $59 \cdot 4$ & 207 & 59.1 & 0.0095 & 0.4612 \\
\hline $\begin{array}{l}\text { Self-inflating child } \\
\text { and adult bag valve } \\
\text { mask(ambu bag }\end{array}$ & 97 & 61.4 & 117 & 60.9 & 214 & 61.1 & 0.0075 & 0.466 \\
\hline Portable suction & 117 & 74.1 & 132 & 68.8 & 249 & 71.1 & 1.183 & 0.1397 \\
\hline $\begin{array}{c}\text { Blood glucose } \\
\text { measurement device }\end{array}$ & 124 & 78.5 & 146 & 76.0 & 270 & 77.1 & 0.292 & 0.297 \\
\hline $\begin{array}{l}\text { Automated external } \\
\text { defibrillator }\end{array}$ & 93 & 58.9 & 114 & $59 \cdot 4$ & 207 & 59.1 & 0.0094 & 0.4612 \\
\hline
\end{tabular}

Table 3. Distribution of study subjects according to gender and their agreement to the following equipments being part of emergency kit. ( ${ }^{*} \mathrm{p}<0.05$ was considered statistically significant) 


\begin{tabular}{|c|c|c|c|c|c|c|c|c|}
\hline KIT & MALE & $\%$ & FEMALE & $\%$ & TOTAL & $\%$ & Z-value & P-value \\
\hline Oxygen face mask & 75 & 39.0 & 43 & 27.2 & 118 & $33 \cdot 7$ & 2.4920 & $0.0130^{*}$ \\
\hline Single use syringe & 144 & 91.1 & 176 & 91.6 & 320 & 91.4 & -0.9680 & 0.3330 \\
\hline $\begin{array}{c}\text { Oro pharyngeal } \\
\text { airway } \\
\end{array}$ & 74 & 38.5 & 41 & $25 \cdot 9$ & 115 & 32.8 & 2.2010 & $0.0280^{*}$ \\
\hline Pocket masks & 112 & 58.3 & 84 & 53.2 & 196 & 56.0 & 1.3290 & 0.1840 \\
\hline $\begin{array}{c}\text { Self-inflating child } \\
\text { and adult bag valve } \\
\text { mask(ambu bag }\end{array}$ & 75 & 39.0 & 44 & 27.8 & 119 & 34.0 & 2.1980 & $0.0280^{*}$ \\
\hline Portable suction & 100 & 52.0 & 71 & $44 \cdot 9$ & 171 & 48.8 & 1.5080 & 0.1320 \\
\hline $\begin{array}{c}\text { Blood glucose } \\
\text { measurement } \\
\text { device }\end{array}$ & 56 & 29.2 & 30 & 18.9 & 86 & $24 \cdot 5$ & 2.1980 & $0.0280^{*}$ \\
\hline $\begin{array}{c}\text { Automated external } \\
\text { defibrillator }\end{array}$ & 21 & 10.9 & 10 & 6.3 & 31 & 8.8 & 1.5080 & 0.1320 \\
\hline
\end{tabular}

Table 4. Distribution of study subjects according to gender and their level of confidence in using the following equipments in the emergency kit: (considered with confident option only). ( ${ }^{*} \mathrm{p}<0.05$ was considered statistically significant)

$2009 .^{7,8}$

In the present study $68.3 \%$ of dental interns has undergone one or the other medical emergency and basic life support training at undergraduate level, whereas a study done by G. J. Atherton et al found that $94.8 \%$ of respondents had undergone medical emergency and basic life support training at undergraduate level9. Out of the 239 respondents who underwent the training programme majority of them $70.3 \%$ considered the programme as moderate, only $26.7 \%$ considered the training programme as good and $0.02 \%$ as poor. The result may be due to the lack of definitive guidelines about the training with medical emergencies in the dental curriculum. A New Zealand study showed more than 50\% of dentists were dissatisfied with undergraduate teaching for medical emergencies and Brazilian dental undergraduates were also found to be similarly dissatisfiedıo. In this study most of the dental interns had a knowledge about adrenalin (69.4\%), Glucose (62.3\%), Hydrocortisone (69.1\%), as the part of

\begin{tabular}{|c|c|c|c|c|c|c|c|c|}
\hline AREA & MALE & $\%$ & FEMALE & $\%$ & TOTAL & $\%$ & Z-value & p-value \\
\hline $\begin{array}{l}\text { Administration of } \\
\text { intravenous drug }\end{array}$ & 92 & $47 \cdot 9$ & 57 & 36.0 & 149 & 42.6 & 2.2260 & $0.0260^{*}$ \\
\hline $\begin{array}{c}\text { Intramuscular } \\
\text { injections }\end{array}$ & 113 & 58.8 & 88 & $55 \cdot 7$ & 201 & $57 \cdot 4$ & 0.5940 & 0.5530 \\
\hline $\begin{array}{c}\text { Maintaining an air } \\
\text { way } \\
\end{array}$ & 61 & 38.6 & 93 & 48.4 & 154 & 44.0 & -1.8410 & 0.0660 \\
\hline Using a glucose meter & 70 & $44 \cdot 3$ & 96 & 50.0 & 166 & $47 \cdot 4$ & -1.0610 & 0.2890 \\
\hline Using a defibrillator & 42 & 21.9 & 28 & $17 \cdot 7$ & 70 & 20.0 & 0.9650 & 0.3340 \\
\hline Administering oxygen & 55 & 34.8 & 89 & 46.3 & 144 & 41.1 & -2.1810 & $0.0290^{*}$ \\
\hline
\end{tabular}

Table 5. Distribution of study subjects according to gender and their competency in these following areas?. ( ${ }^{*} \mathrm{p}<0.05$ was considered statistically significant) 
emergency drug kit whereas the knowledge of other drugs were poor. This finding was similar in study conducted by Haas DA in which respondents had a good knowledge in identifying the four common drugs like adrenaline glucose, oxygen and glycerly trinitrate. ${ }^{11}$ The knowledge was unsatisfactory, particularly when discussing drugs like prednisolone and chlorpheniramine maleate and very few respondents recognized these as being essential drugs. Their confidence in using the drug were highest with adrenalin (69.4\%), glucose $(62.3 \%)$, hydrocortisone (69.1\%). This finding was similar with that done by Praveen S. Jodalli in 2012. ${ }^{2}$

In this study majority of the dental interns considered single use syringe (94.6\%) and oxygen face mask (91.1\%) as a part of emergency equipments. In contrary to this, a study done by Ehigiator O in 2014 reported that most of the dental interns consider ambu bag (74.2\%), bronchodilator spray $(64.5 \%)$ and pocket mask (49.6\%) as a part of emergency equipments. ${ }^{6}$ The confidence level of using various equipments during medical emergency were low among dental interns except in case single use syringe (91.4\%). Significantly more number of males in comparison to females were confident in using oxygen face mask, maintaining oro pharyngeal airway, administering self-inflating child and adult bag valve mask (ambu bag) and in using blood glucose measurement device. This suggests that although training is received in the theoretical aspect of emergencies, participants are not particularly confident to treat emergencies and may require further practical training.

Present study showed that competency in performing various procedures during emergency like, administration of intravenous drug, intramuscular injections, maintaining an air way, using an ambu bag/bag valve mask, using a glucose meter, using a defibrillator, administering oxygen were not satisfactory. A study done by Chapman found that only $55 \%$ of Australian dental graduates felt competent in cardiopulmonary resuscitation (CPR) upon graduation. ${ }^{12}$

Our study found that the dental interns are not completely aware of and are not being trained effectively in managing of all emergency situations. It is conspicuous that neither dental interns are capable of competently managing a medical emergency when they occur nor they have a good knowledge about drugs and equipment.

\section{CONCLUSION}

The study has provided an insight into deficiencies in the undergraduate training programs in dealing with medical emergencies. Although measures have been taken to improve on this aspect still there exist voids. Dental graduates had a superficial knowledge of medical emergencies, drugs and equipments. Their confidence level and competency in performing various procedure and in using equipments during emergency were not satisfactory. They expect this topic should be an integral part of their curriculum and majority of them perceived the need for further training in medical emergency management.

\section{REFERENCES}

1. Wilson MH, McArdle NS, Fitzpatrick JJ, Stassen LF. Medical emergencies in dental practice. J Ir Dent Assoc 2009; 55(3):134-43.

2. Balmer C, Longman L The Management of Medical Emergencies: A Guide for Dental Care Professionals. MA Healthcare Limited 2008.

3. Gupta T, Aradhya MRS. Preparedness for Management of Medical Emergencies Among Dentists in Udupi and Mangalore, India. J Contemp Dent Pract 2008;9(5):92-9.

4. Shampaine GS. Patient assessment and preventive measures for medical emergencies in the dental office. Dent Clin North Am 1999;43(3):383-40o.

5. Carvalho RM, Costa LM, Marcelo VC. Brazilian Dental Students' Perceptions About Medical Emergencies: A Qualitative Exploratory Study. J Dent Educ. 2008;72(11):1343-9.

6. Ehigiator O, Ehizele AO, Ugbodaga PI. Assessment of a Group of Nigerian Dental Students' Education on Medical Emergencies. Annals of Medical and Health Sciences Research. 2014;4(2):248-52.

7. Fast TB, Martin MD, Ellis TM. Emergency preparedness: a survey of dental practitioners. J Am Dent Assoc 1986;112:499-501.

8. Adewole RA, Sote EO, Oke DA, Agbelusi AG. An assessment of the competence and experience of dentists with the management of medical emergencies in a Nigerian teaching hospital; Nig Q J Hosp Med 2009: 19:190-4.

9. Atherton GJ, McCaul JA, Williams SA. Medical emergencies in general dental practice in Great Britain Part 3: perceptions of training and competence of GDPs in their management. Br Dent J. 1999;186(5):234-7.

10. Newby JP, Keast J, Adam WR. Simulation of medical emergencies in dental practice: development and evaluation of an undergraduate training 
programme. Australian Dental Journal 2010;55: 399404.

11. Haas DA. Management of medical emergencies in the dental office: conditions in each country, the extent of treatment by the dentist. Anesth Prog. 2006; 53:20-4.

12. Chapman PJ. Medical emergencies in dental practice and choice of emergency drugs and equipment: a survey of Australian dentists. Aust Dent J. 1997;42:103-8.

Source of support: Nil, Conflict of interest: None declared

Cite this article as:

Paul A, Naviwala GA, Prakash D. Knowledge and Experience about Medical Emergencies

among Dental Interns in Bangalore City. Int Healthc Res J. 2019;2(11):270-275. doi:

10.26440/ihrj.v2i11.200

\section{AUTHOR AFFILIATIONS:}

1. Senior Lecturer, Department of Public Health Dentistry, KMCT Dental College

2. Medical Officer (Dental), Malvani

\section{*Corresponding Author:}

Dr. Arun Paul

Senior Lecturer

Department of Public Health Dentistry

KMCT Dental College
For article enquiry/author contact details, e-mail at: editor.ihrj@gmail.com,editor@ihrjournal.com 